\title{
RSE - Caso líder en \\ consumo inteligente
}

Versión final: agosto 2010

Equipo de Comunicaciones Corporativas

de MasterCard para la región de

Latinoamérica y el Caribe ${ }^{(*)}$

\begin{abstract}
Resumen: Este artículo corresponde a un caso líder desarrollado por el Equipo de Comunicaciones Corporativas de Mastercard para la región de Latinoamérica y el Caribe, en el marco de la gestión de Responsabilidad Social Empresaria, con un programa basado en consumo inteligente, sobre la temática de educación financiera. A través del uso de las últimas tendencias en tecnología y social media, incluyendo un sitio 2.0 , podcasts, y herramientas interactivas, además de actividades offline y múltiples alianzas, MasterCard se propuso ayudar a los consumidores latinoamericanos a manejar su dinero en forma más eficiente y responsable.
\end{abstract}

Palabras claves: Comunicación Corporativa - Comunicación Digital - Comunicación Empresaria - Comunicación Institucional - Consumo Inteligente - Dircom - gestión comunicacional - Imagen Corporativa - Management - Marcas - Marketing - mercadeo - organización - públicos - Redes Sociales - Relaciones con la Comunidad - Relaciones Institucionales - Relaciones Públicas - Reputación Corporativa - Responsabilidad Social Empresaria - Social Media.

[Resúmenes en inglés y portugués y currículum en la página 21]

\section{Antecedentes del programa}

Tras realizar un estudio en el ambiente económico de América latina y el Caribe, MasterCard observó que existía un vacío apremiante en la educación financiera de la región y reconoció que los consumidores se enfrentan a desafíos similares en cuanto a información básica en manejo de dinero, planeamiento de presupuestos y uso de tarjetas de débito o crédito para los cuales no hay herramientas disponibles simples y de fácil acceso.

De hecho, en Brasil el $81 \%$ de los consumidores adjudica la responsabilidad de ser educados en relación sus finanzas personales a las empresas de tarjetas y bancos, mientras que a gobiernos solamente un 63\%, y en México los números son similares. Este es uno de los factores que motivó la concepción del programa como forma de satisfacer esas expectativas.

"MasterCard se ha comprometido a promover la educación financiera y educar a los consumidores de todo la región través de herramientas que los ayuden a adquirir conocimientos financieros sólidos y a asumir el control de su futuro económico", dijo Marcus Molina, Vicepresidente de Comunicaciones Corporativas de MasterCard para la región de Latinoamérica y el Caribe. Recién comenzamos a vivir más agudamente la segunda revolución digital. La primera culminó en el año 2000, cuando explotó la burbuja de las empresas "puntocom" y los más escépticos dejaron de creer en las oportunidades que brindaba la Web, comenta Molina. Sin embargo, el Internet volvió a revolucionarnos con el nuevo fenómeno de Social Media. 
Para alcanzar buenos resultados, una plataforma de Social Media requiere de la tecnología necesaria que facilite el acceso a contenido generado por los usuarios y sobretodo que disponga de herramientas interactivas para hacer posible un verdadero proceso de retroalimentación. Sin embargo, lo que garantiza el éxito de un programa o de una campaña en este rubro, es que detrás de todo esto que también exista una idea creativa que alimente el fuego.

En otras palabras, se presentaba en la región una oportunidad tanto en el área de educación financiera, como de llegarles a mas y mas consumidores a través del Internet. La gente necesitaba herramientas, recursos y guía para controlar y administrar sus finanzas personales de manera más ordenada y MasterCard desarrolló una campaña destinada a capitalizar esa oportunidad. “...los consumidores se enfrentan a desafíos similares en cuanto a información básica en el manejo de dinero, planeamiento de presupuestos, uso de tarjetas de débito o crédito y prevención de fraude...", comentó Molina.

\section{El Programa Consumo Inteligente de MasterCard}

En el 2007 MasterCard lanzó el programa Consumo Inteligente ${ }^{1}$ (www.consumointeligente. org) en México y Brasil y desde entonces, fue expandiendo su alcance al resto de Latinoamérica y el Caribe al tiempo que aumentó los recursos y las herramientas disponibles.

El desafío fue el de crear un programa que estuviera disponible las 24 horas, durante los 7 días de la semana; a la mayor cantidad de consumidores posibles, y que fuera regionalmente consistente y localmente apropiado. Pero sobretodo que le permitiera a los latinoamericanos y caribeños acceder a herramientas y recursos que les provean conocimientos prácticos, útiles y sólidos para ayudarlos a administrar su dinero de forma óptima, a desarrollar hábitos positivos de gasto y ahorro; y que los eduque sobre el uso responsable de los medios de pagos electrónicos. Para lograrlo, la plataforma cuenta con múltiples herramientas interactivas y material disponible con contenido de finanzas y de actualidad dirigidos al público general.

"Los consumidores hoy día enfrentan una compleja gama de opciones financieras, y con frecuencia no cuentan con ninguna, o muy poca educación financiera que les permita guiarse para elegir de forma inteligente como van a utilizar su dinero. Ya sea que los consumidores estén llevando a cabo gastos, ahorros o inversiones, se ven obligados constantemente a tomar decisiones financieras importantes sin la experiencia o la orientación necesarias que les ayuden a mantenerse por la senda correcta", continuó Molina.

\section{Elementos del programa}

El planteo era desarrollar una plataforma sólida de Internet en donde a través de herramientas interactivas se brindara contenido para que los usuarios pudieran acceder de forma ágil y rápida. Partiendo de este punto, MasterCard creó un sitio 2.0 con una gran diversidad de elementos que se adaptan de forma específica al idioma y los intereses locales del visitante.

"El programa se creó de forma tal que contuviera herramientas interactivas para empujar el contenido a los usuarios y que ellos pudieran accederla de forma ágil y rápida. De ahí, nuevas herramientas y funcionalidades se irán incorporando poco a poco con el objetivo de mantener el programa al día con las necesidades de los consumidores", dijo Molina.

Por el momento, los visitantes al sitio pueden navegar fácilmente por el contenido educacional 
para encontrar información, consejos y herramientas financieras, así como módulos educacionales interactivos sobre una amplia variedad de temas, desde el uso de las tarjetas de crédito y débito hasta el planear de forma fácil un presupuesto y los ahorros, con el fin de promover el éxito de la administración financiera familiar.

Los recursos destinados a ayudar a los consumidores a tomar el control de sus finanzas personales son los siguientes:

- Universidad Financiera: es un espacio en el sitio con contenido presentado en un estilo How To, de modo que el consumidor pueda fácilmente llevar a la práctica los conceptos aprendidos. El contenido se encuentra agrupado en seis módulos temáticos: Haciendo un Presupuesto, Finanzas Familiares, Evite Endeudarse, Maneras de Ahorrar, Conociendo el Crédito y la Tarjeta de Débito.

- Herramientas Interactivas: Fueron diseñadas para ayudar a los consumidores a gestionar sus decisiones de manera más conveniente y para mejorar sus conocimientos en el manejo de las finanzas personales. Algunas de ellas son:

- Preparación del presupuesto

- Pruebe su conocimiento sobre el crédito

- Hoja de trabajo de ingresos y gastos

- ¿Qué tan bien conoce su tarjeta de crédito?

- Señales de advertencia de endeudamiento

1. Cápsulas Educativas Animadas: De acuerdo con un estudio realizado por MasterCard en la región, los consumidores prefieren aprender sobre asuntos financieros por medio de situaciones reales de una familia. Por lo tanto, la imagen visual del programa esta representada por una familia compuesta de cuatro personajes virtuales, la mamá, el papá y dos hijos en edad universitaria. Estas cápsulas animadas consisten en una serie de módulos de video con una duración aproximada de 2 minutos y medio en donde los miembros de la familia interactúan y toman decisiones sobre situaciones de la vida real asumiendo consejos prácticos sobre cómo administrar sus finanzas. En uno de los videos incluyen tips sobre cómo realizar compras seguras por Internet y tiene como objetivo desmitificar el miedo de los consumidores frente a esta situación.

"En el mercado digital y no digital actual hay mas información que nunca", explicó Molina. "Los medios de comunicación han ampliado la cantidad de contenido de manera impresionante. Hace quince años teníamos emisoras de radio, TV y medios impresos; hoy existe una cantidad tremenda de medios que comunican, principalmente a nivel intenet, donde a veces la información es demasiada. En ese sentido, la adecuación de la información es crítica”.

2. Mi\$ter/Mi\$ Finanzas: En varios países de la región el sitio incluye expertos financieros. Se trata de bloggeros que no trabajan en MasterCard, sino que están activos en el ámbito de las finanzas de cada país. Para lograrlo, el sitio fue diseñado con una plataforma de blog integrada, donde los Mi\$ter/Mi\$ Finanzas pueden subir podcasts, publicar entrevistas, compartir información, consejos útiles y experiencias que han aprendido a lo largo de su vida personal, familiar y financiera. Además, para estar actualizados sobre novedades, los usuarios pueden suscribirse al contenido por RSS y escuchar los podcast en iTunes. Lo interesante es que los 
consumidores o usuarios pueden hacer preguntas y comentar sobre el contenido generado por los Mi\$ter o Mi\$ \$ Finanzas tanto para aclarar sus propias dudas como las de otras personas que hayan expuesto sus preguntas en la plataforma web.

3. Panel de Expertos Financieros: Para aquellos países que no cuentan con un Mi\$ter o Mi\$\$ Finanzas localmente, MasterCard incluyó un Panel Financiero Regional con expertos financieros provenientes de diferentes países de América Latina como México, Brasil, Costa Rica, República Dominicana y Puerto Rico. Allí también ofrecen sus perspectivas y consejos con los consumidores de todas partes de la región, y proporcionan una experiencia educacional interactiva y sumamente valiosa. El objetivo es seguir creciendo hasta conseguir que todos los países tengan una persona dedicada exclusivamente al $b \log$.

\section{Estrategia de llegada por internet}

Por un lado, MasterCard diseñó un sitio 2.0 implementando las últimas tendencias en tecnología y, por el otro, apoyó su estrategia de llegada en Social Media. Si bien el fenómeno de las redes sociales no es nuevo en el mundo de la comunicación, el marketing y las relaciones públicas, difícilmente se presenta de manera tan completa e integral como en el caso del programa Consumo Inteligente. Los elementos que utilizó MasterCard para realizar el outreach fueron cuidadosamente pensados para alcanzar una comunicación más eficiente con los usuarios, los periodistas y todo aquel pudiera interesarse en el programa. Todos ellos presentaron el contenido del sitio de manera diferente, de acuerdo con el público al que estaba destinado:

\section{Presentación Web}

Donde MasterCard explica el por qué está trabajando arduamente en educar a los consumidores de la región. Se diseñó una presentación para lanzar el programa a nivel regional en el 2009 utilizando el formato de video con la tecnología Flash.

\section{Social Media Outreach}

Se crearon perfiles sociales en Facebook, Twitter, Slideshare, Orkut, Flickr, LinkedIn y YouTube con el objetivo de llegar a mayor cantidad de usuarios y periodistas e impulsar el acceso y la conveniencia de estos sitios.

\section{Hoja de Datos/ Media Kit}

Está diseñado y hosteado en Issuu.com que es otro sitio en donde se comparten documentos digitales. Allí se incluye una descripción del crecimiento, los componentes nuevos e interactivos y la visión general del programa acompañado de imágenes y viñetas diseñadas para acompañar la lectura.

\section{El programa en las Comunidades}

Como parte de la expansión natural del programa y de su objetivo innato de seguir llegando a más y más consumidores alrededor de la región, el año pasado, el programa Consumidor Conciente formó una alianza con la segunda "favela" más grandes de San Pablo: Paraisópolis, para ofrecerle a esa comunidad educación financiera. Allí se brindan seminarios y cursos de 
educación financiera para la población, que tiene más de 100 mil habitantes en su mayoría de las clases D y E. El objetivo es el de promover buenas prácticas en materia de finanzas personales para esta comunidad careciente de este tipo de recursos.

Así como con esta alianza con Paraisópolis, MasterCard sigue expandiendo su plataforma offline en otros mercados a través de alianzas con diferentes entidades como universidades, organizaciones sin fines de lucro, entidades financieras, etc. para brindarles a consumidores información valiosa sobre el manejo del dinero en donde estén, fuera de línea.

Con estas alianzas, MasterCard no solo les provee información en forma de charlas educativas o seminarios en diferentes foros, comunidades carentes o universidades, sino también materiales impresos, como panfletos, hojas de consejos, pancartas y posters.

Las repercusiones de Consumo Inteligente benefician tanto a los consumidores en general como también a las economías locales. Los consumidores aprenden a manejar las finanzas personales y familiares, planificar los gastos, desudas e inversiones, y a enfrentar perdidas de la mejor manera. Las economías locales -entidades bancarias, comercios, gobiernos, etc.- en cambio se favorecen del ambiente próspero que deriva de un consumidor capacitado e informado.

"Sostenemos la idea de que un consumidor informado es un consumidor que nos ayuda; lo peor que nos puede pasar a nosotros como compañía de medios de pago es que un consumidor no pueda usar nuestros productos eficientemente. Al no saber utilizar los productos los consumidores se endeudan, no aprovechan el potencial del producto y generalmente perdemos al consumidor", concluyó Molina.

\section{Resultados}

El programa Consumo Inteligente fue presentado en dos mercados claves para MasterCard, extendiéndose luego a otros tres países. Más recientemente la plataforma educativa se ha implementado en toda la región, incluyendo países anglo-parlantes principalmente ubicados en el Caribe. Es decir que hasta hoy, Consumo Inteligente sirve a consumidores en los 20 países de Latinoamérica y el Caribe.

Las métricas del programa son multidimensionales y dinámicas. Actualmente, y desde su creación el portal de Consumo Inteligente ha recibido más de 230 mil visitantes únicos quienes junto a visitantes recurrentes del portal han visto más de 730 mil páginas del portal. Visitantes del portal también se pasan un promedio de 9 minutos en la página.

En términos del número de páginas vistas desde el 2007, el programa ha crecido un $96 \%$ y un $82 \%$ en el número de visitantes únicos, lo cual es un claro testimonio de su éxito. Como si esto fuera poco, el promedio de visitantes mensuales en los últimos seis meses sobrepasan 10 mil y el promedio de páginas vistas en los últimos seis mese sobrepasan 30 mil.

A diferencia de muchas empresas que buscan utilizar herramientas digitales, MasterCard descubrió la manera de conseguir una relación sinérgica entre ellas, convergiendo en una plataforma que las integra en un todo armónico. Muchas empresas se remiten a tener un perfil en Facebook o en Twitter, otras continúan haciendo tan sólo comunicados de prensa e incluso podemos encontrar aquellas que intentan ingresar al mundo 2.0 con campañas aisladas en YouTube. En cambio, el programa Consumo Inteligente fue diseñado con una visión holística e integrado - entre actividades en el internet y offline; algo que es difícil de observar en estos tiempos que corren. 
Las mediciones que se realizan están dirigidas a cuantificar el impacto en notas de prensa, el número de seguidores en Twittery Facebook, los downloads, los videos vistos en YouTube, el uso de las herramientas interactivas y, entre otras cosas, los comentarios en los blogs.

Finalmente, en cuanto a la divulgación del programa, MasterCard se propuso, abarcar todos los canales presentes en el mundo online y facilitar el trabajo de los periodistas de llevar la noticia al mundo offline. A través de las animaciones, la web presentation, los comunicados de prensa sociales, la plataforma 2.0 y el outreach de medios está efectivizando sus objetivos; pero su trabajo aún no termina.

\section{Notas}

1 Llamado Consumidor Consciente (www.consumidorconsciente.org) en portugués y Smart Consumer (www.smartconsumer. ws) en inglés.

Summary: This article corresponds to a leading Corporate Social Responsibility program developed by Mastercard's Corporate Communications Team in the Latin America and Caribbean region, based on wise spending and the financial education thematic. Through the use of the latest trends in technology and social media, including a 2.0 website, podcasts and interactive tools, in addition to offline activities and multiple alliances, MasterCard works to help Latin American consumers manage their money in the most efficient and responsible way.

Key Words: Brand - Digital Communication - communication management - Community Relations - Corporate Communications - Corporate reputation - Corporate Image - Dircom - Institutional Communication - Institutional Relations - Management - Marketing - organization - Public Relations - Social Corporate Responsibility - Social Media - Social networks - stakeholders - wise money management.

Resumo: Este artigo refere-se a um caso desenvolvido pela Equipe de Comunicações Corporativas da MasterCard para a região da América Latina e Caribe, e também ao marco da gestão de Responsabilidade Social Empresarial, com um programa baseado em consumo consciente, sob a temática da educação financeira. Utilizando as últimas tendências em tecnologia e mídia social, incluindo ferramentas 2.0 e interativas, podcasts, além de atividades offline e múltiplas paqrcerias, a MasterCard se propôs ajudar aos consumidores latinoamericanos a gerenciar seu dinheiro de forma mais eficiente e responsável.

${ }^{*}$ ) Este artículo corresponde a un caso líder desarrollado por el Equipo de Comunicaciones Corporativas de Mastercard para la región de Latinoamérica y el Caribe, en el marco de la gestión de Responsabilidad Social Empresaria, con un programa basado en consumo inteligente, sobre la temática de educación financiera para ayudar a los latinoamericanos a sacarle partido a su dinero. Para ello, se reflexiona acerca de los ejes del programa y de la plataforma comunicacional que se utilizó para su lanzamiento e implementación. Los integrantes del Equipo de Comunicaciones Corporativas de Mastercard son: Marcus Molina -Vicepresidente de Co- 
municación Corporativas para Latinoamérica y el Caribe-, Aimeé Alvarez, Fernando Arango, Janet Rivera, Andrea Denadai, Angélica Gutiérrez, Jeannette Rodríguez, Alina Dalmau, Adriana Deben, Claudia Muraro, Lillian Salazar y Rosalynn Salinas. 